The following is an examination of how foundations have been responding to the current economic crisis, based on the early 2009 survey responses of more than 1,200 U.S. foundations. It is part of an ongoing Foundation Center research series intended to shed light on the impact of the economic downturn on the nonprofit sector.

\title{
Foundations Address the Impact of the Economic Crisis
}

\author{
By Steven Lawrence, Senior Director of Research
}

As the ongoing economic crisis reaches a scale and duration not seen in the post-war period, foundation behavior during past downturns may become a less precise predictor of how funders will cope with current reality. To provide an up-to-date assessment of how foundations are addressing today's challenges, the Foundation Center surveyed more than 1,000 of the nation's largest foundations in early 2009 (see "About the Survey" on page 3 for details).

Their responses indicate that nonprofits face a challenging environment for grantseeking. As reported in the Center's recent Foundation Growth and Giving Estimates report, overall foundation giving is expected to decrease in the range of the high single digits to low double digits in $2009,{ }^{1}$ and close to half of surveyed foundations predict reductions in the number and size of their grants. Nonetheless, foundations are considering strategies beyond grantmaking to fulfill their missions and using various resources to minimize the impact of asset losses on giving. A number of foundations have also incorporated lessons from the last downturn to help them better cope with the current crisis.

\section{What Should Grantseekers Expect in 2009?}

This year and next will be a particularly challenging time for both organizations seeking new sources of support and for recently established entities - 43 percent of surveyed foundations expect to reduce the overall number of grantees they fund in 2009 and 46 percent anticipate decreasing the number of new grantees they will fund. Organizations in need of capital support will also be particularly hard hit, with over onethird of foundation respondents (37 percent) reporting that they will reduce the amount of capital support they provide.

At the same time, grantees with existing foundation relationships have already begun receiving smaller awards and rejection notices citing the impact of the economic crisis. Close to two-thirds of foundation

\section{Key Findings}

- Close to two-thirds of surveyed foundations predict reductions in the number and/or size of their grants in 2009.

- Most respondents expect to maintain the number of program and geographic areas they currently support.

- Two out of five respondents expect to dip into their endowment principal to fund their 2009 grants budgets.

- Over half of respondents anticipate engaging in more non-grantmaking activities in response to the economic downturn.

- More than one-third of community foundation respondents are engaging in special initiatives in response to the economic crisis, compared to 14 percent of respondents overall. 
respondents (63 percent) expect to reduce the number of grants they will award in 2009 and/or the size of their grants. A substantial share also anticipate reducing the number of multi-year grants (44 percent). Larger foundations - those giving $\$ 10$ million or more-were somewhat less likely to anticipate reducing the size of their grants (38 percent) and the number of multi-year grants (39 percent).

The one source of possible optimism for grantees in both the near and long term is that the vast majority of respondents (80 percent) expect to maintain their current number of program areas, and 3 percent anticipate increasing the number of areas they support. Likewise, all but about 6 percent of respondents expect to maintain or increase the geographic areas they target. Consistent with findings on foundation activities during the last economic downturn, ${ }^{2}$ this suggests that most foundations will not abandon their grantmaking priorities-from health to the arts to international grantmaking - despite the severity of current economic conditions.

\section{Are Foundations Directly Addressing the Impact of the Economic Crisis?}

A total of 168 respondents to the Foundation Center's 2009 survey indicated that they are launching a special initiative, making exceptional grants, or offering loans and other program-related investments (PRIs) in direct response to the economic crisis. While this 14 percent share may seem relatively small given the scale of the economic crisis, it's likely that many funders are responding in an equally critical way by seeking to maintain stable levels of givingor minimize reductions in funding-for their grantees. Links to the public statements of the top 100 foundations by giving and other selected funders on their economic crisis response are available at foundationcenter.org/ focus/economy. ${ }^{3}$

Community foundations are mounting a particularly vigorous response to the economic downturn. More than one-third (35 percent) of community foundation respondents indicated that they were engaging in special initiatives to help their communities cope with the local fallout from this global crisis, such as rising unemployment and homelessness. Larger foundation respondents-those giving $\$ 10$ million or more annuallywere more likely to be providing exceptional support in direct response to the crisis. Since late 2008, the Foundation Center has been collecting information on the grants and PRIs made by foundation and corporate donors in direct response to the economic crisis and making it available via an interactive map at foundationcenter.org/ focus/economy. ${ }^{4}$

\section{Anticipated Changes in 2009 Foundation} Grantmaking Strategies

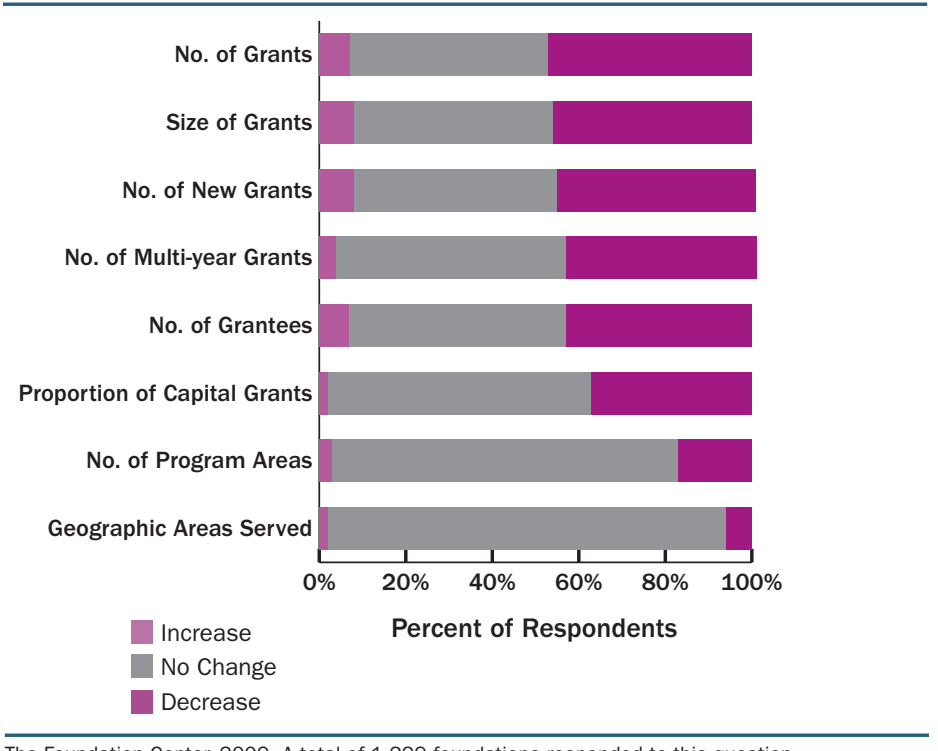

Foundations Making a Direct Response to the Economic Crisis

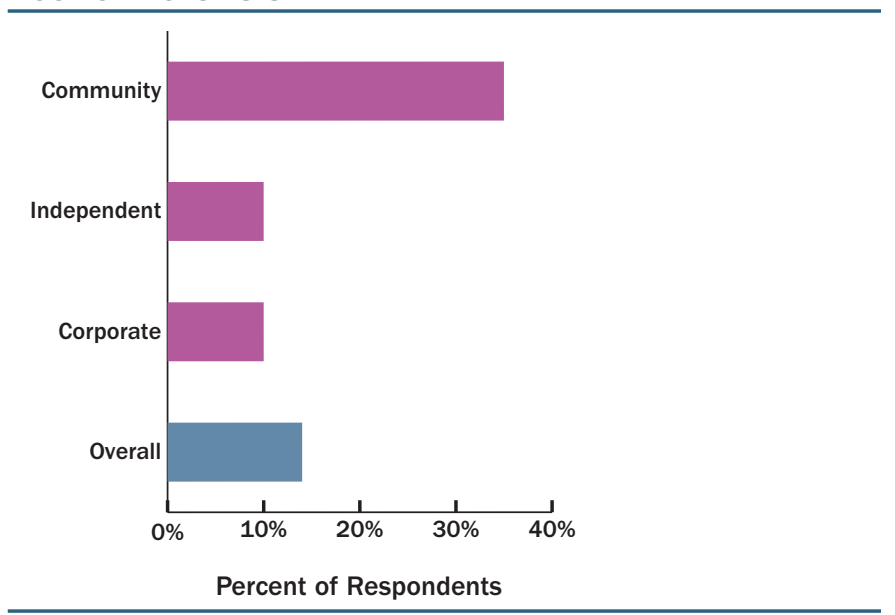

SOURCE: The Foundation Center, 2009. A total of 168 respondents indicated that they have or will launch special initiatives, make exceptional grants, or offer loans and other program-related investments (PRIs) in direct response to the economic downturn. 
While these foundations are providing essential support to meet the specific, urgent needs created by the current economic crisis, it is not coming without a cost to other funding areas. Three out of five (61 percent) of the respondents that are making exceptional commitments indicated that they were reallocating some of those funds from existing grants budgets, with almost half citing reallocations as the exclusive source of this support.

Among other commonly cited sources of support for economic crisis-related giving were discretionary funds (29 percent) and new gifts or bequests from donors (23 percent)—although the latter was reported primarily by community foundations. About 17 percent of respondents indicated that they would dip into their endowment principal to make exceptional commitments in response to the economic crisis, while just over 10 percent were tapping their reserve funds.

\section{Beyond Grantmaking, What Types of Changes Do Foundations Expect to Make?}

The current economic situation may have reduced the resources most foundations have available to make grants, but that has led many funders to identify other strategies for achieving their goals. In fact, over half of respondents (54 percent) indicated that, in response to the economic downturn, they anticipate engaging more in a range of non-grantmaking activities.

Fully two-thirds of surveyed funders said they are seeking to engage in more collaborations and partnerships, while about one-third (36 percent) expect to initiate more convenings. Other non-grantmaking strategies cited by at least one out of five respondents included engaging in more foundation staff-led activities, providing more technical assistance, offering more bridge/ emergency financing, and engaging in more advocacy. In addition, more than one out of ten respondents indicated that they would be making more program-related investments (PRIs).

\section{What Did Foundations Consider When Determining Their 2009 Grants Budgets?}

Establishing a grants budget following a year when overall foundation assets dropped an estimated 21.9 percent posed unique challenges for grantmakers.

Regardless of strategies they may have used to smooth out the impact of fluctuations in the value of their assets on giving, no approach could adequately compensate for the unprecedented loss of charitable resources. Yet based on responses to the latest survey, the Foundation Center estimates that giving in 2009 will decline by a far lower percentage - from the high single digits to the low double digits- than did assets in the prior year. ${ }^{5}$ This suggests that many foundations were taking a broader range of factors into account when determining this year's grants budgets.

\section{Source of Funds for Economic Crisis-related Giving}

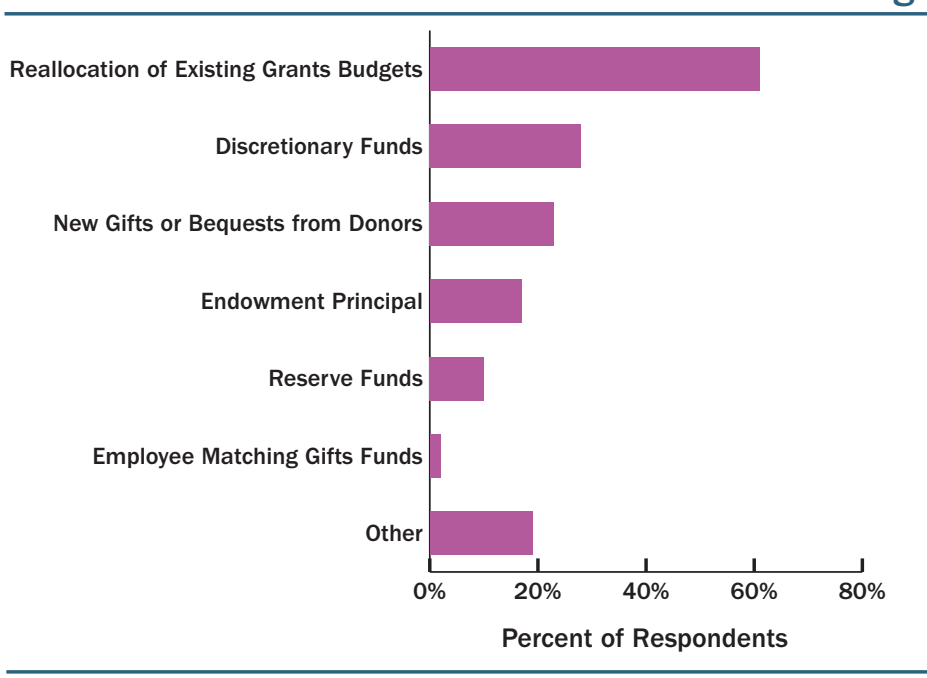

SOURCE: The Foundation Center, 2009. A total of 168 foundations responded to this question.

\section{About the Survey}

In January 2009, the Foundation Center mailed its annual "Foundation Giving Forecast Survey" to approximately 5,000 large and mid-size U.S. independent, corporate, and community foundations. The survey included questions on foundations' giving and assets in 2008, the outlook for giving in 2009 and 2010, and how foundations are responding to the economic downturn. A total of 1,243 foundations provided usable responses as of April 2009. By foundation type, 961 independent foundations, 172 community foundations, and 110 corporate foundations responded. (For more information, see Appendix B in Foundation Growth and Giving Estimates, 2009 Edition.) 
When asked to identify the factors that influenced decision-making around their foundations' 2009 grants budgets, most respondents cited three as being somewhat or very influential: board and leadership decisions (88 percent), the economic climate and market conditions (88 percent), and their foundation's strategic priorities (80 percent). Just over half of respondents (52 percent) also cited outstanding grant obligations as being somewhat or very influential in their decision-making. But in the absence of any baseline information to serve as a point for comparison, it is not clear whether these findings are similar or different from those that might have been obtained following a more typical year of growth in assets.

What differentiates 2009 is in the way grantmakers plan to use their available resources to meet their grants budgets. As in a typical year, the vast majority of respondents (88 percent) plan to use investment income to meet their grantmaking budget. But what is atypical is that close to two out of five respondents (39 percent) expect to dip into their endowment principal to make grants. This is especially notable given that the assets of most of these funders have already been greatly diminished by the economic crisis. Among these respondents, independent foundations are the most likely to draw on their endowments ( 43 percent), while community foundations are least likely to do so (5 percent). Other sources of support that respondents expect to use to meet their grants budgets in 2009 include new gifts and bequests from donors

(17 percent), discretionary funds

(13 percent), and reserve funds

(9 percent).

Some foundations smooth out the impact of fluctuations in the value of their assets by determining their grants budgets based on an average of their asset values over several prior years. According to the survey, most foundation respondents (79 percent) do base their grants budgets primarily on the value of either their past, current, or projected assets, with the largest share of foundations (40 percent) using the value of their prior fiscal year's assets for their calculations. However, approximately 22 percent calculate their grants budget based on a two-to-five-year rolling average of their asset values, which enables them to temper years of slower growth or losses with positive years, thereby ensuring more stable levels of giving.

Community foundations were far more likely to report engaging in asset averaging ( 56 percent) than independent (17 percent) or corporate (8 percent) foundations. By size of giving, larger and midsized foundations - those giving $\$ 1$ million or more-were slightly more likely to average assets when determining grants budgets (24 percent) than were smaller foundations (19 percent). Of course, the extremity of 2008 asset losses means that, even with averaging, giving by most

\section{Types of Non-Grantmaking Activities Foundations} Anticipate Increasing in 2009

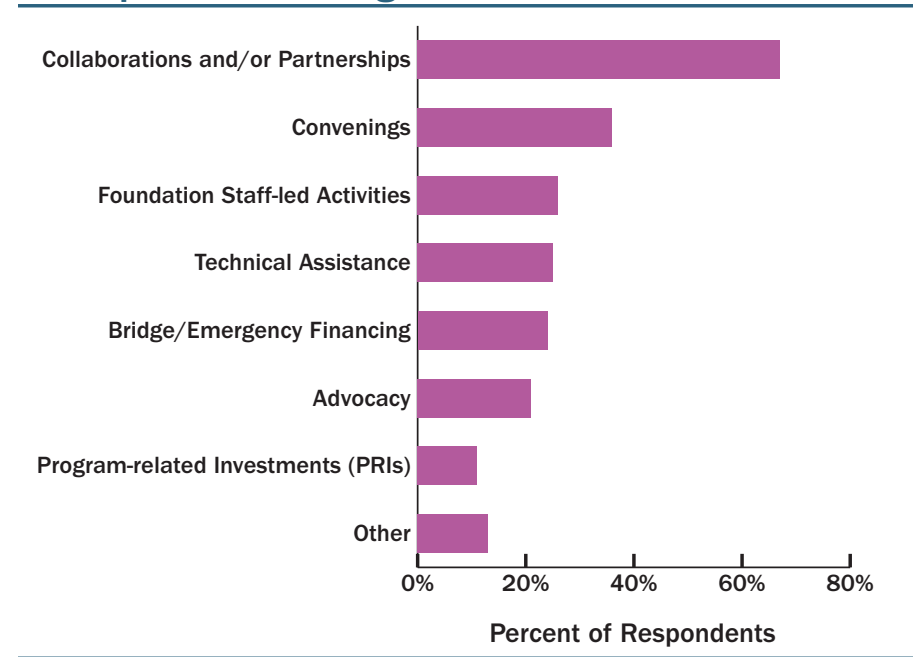

SOURCE: The Foundation Center, 2009. A total of 678 foundations indicated that they would be increasing their non-grantmaking activities in response to the economic crisis, representing 54.5 percent of overall survey respondents.
Source of Funds for Foundations' 2009 Grants Budgets

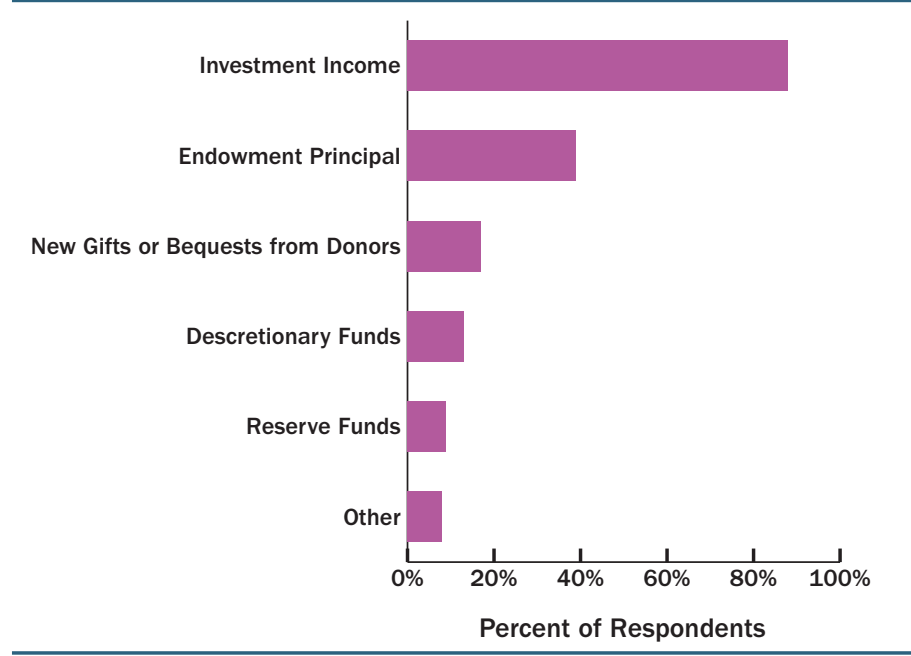


foundations would still decline in 2009. Moreover, without a robust recovery in the market in 2009which appears unlikely-even foundations that average assets will likely have to decrease giving further in 2010, as they run out of growth years to average into their calculations.

\section{Were Foundations Better Prepared to Face the Current Downturn?}

The economic downturn that took place earlier in this decade (2000-02) followed a period of unprecedented growth in foundation resources and left a number of foundations with large commitments that had to be fulfilled with markedly diminished assets. This experience, combined with the relatively volatile period of economic growth that followed, led a number of foundations to make changes in the way they operate that they believe better prepared them to face the current downturn.

Overall, nearly one-third of respondents (32 percent) reported having made changes in the way they operate as a result of the last downturn to better prepare them to address future slowdowns.

Community foundations were most likely to have reported making a change ( 45 percent), followed by corporate (37 percent) and independent (30 percent) foundations. By foundation size, the largest funders - those giving $\$ 10$ million or more-were most likely to have made a change (44 percent).
The largest share of these respondents (29 percent) indicated that they had made changes in their investment management. Yet, there was no single investment strategy cited by a majority of funders, and their responses ranged from diversifying their portfolios to moving to more conservative investments to changing investment advisors. Other funders indicated that they had moved to calculating their grants budgets based on a rolling average of their asset values over several years (5 percent), and a few reported having changed their payout rate (3 percent).

On the expenses side, several foundations reported having reduced staffing and other administrative costs as a result of the last downturn (9 percent), which better prepared them to face the current crisis. In terms of grantmaking strategies, 8 percent of respondents indicated that they had either reduced or eliminated multi-year grants, while 4 percent noted that they had made their grantmaking more focused and strategic.

\section{What Impact Will the Current Downturn Have on Foundation Philanthropy in the Future?}

The Foundation Center's latest survey provides perspective on how foundations are expecting to respond to the economic downturn while still in the midst of the crisis. Yet their responses raise more questions for the future: Will foundations remain as committed to collaboration and partnerships after their grants Primary Factor Determining
Foundation Grants Budgets

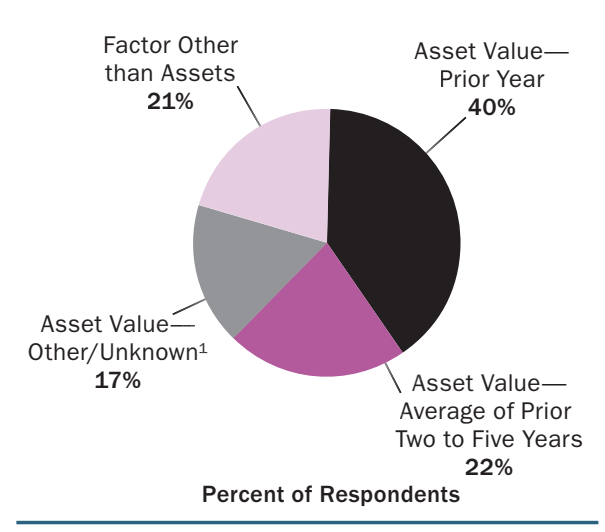

SOURCE: The Foundation Center, 2009. A total of 1,239 foundations responded to this question.

${ }^{1}$ Includes foundations that use a projection of current-year asset values or other specified asset criteria; or that indicated their assets were the primary factor they used in determining their grants budgets, without specifying how they made their calculations.

budgets begin to rebound? Will they continue to engage as extensively in non-grantmaking activities to support their missions? Will the issues raised by this crisis, such as homelessness and unemployment, lead to a long-term refocusing of foundations' grantmaking priorities? Foundations will undoubtedly evolve as a result of having weathered this crisis, although it remains to be seen whether practices emerging in the current economic climate will persist to some degree once the economy begins to recover.

\section{Endnotes}

1. See Lawrence, S., and R. Mukai, Foundation Growth and Giving Estimates: Current Outlook, New York: Foundation Center, 2009.

2. See Lawrence, S., Do Foundation Giving Priorities Change in Times of Economic Distress?, New York: Foundation Center, 2008.

3. See also McGill, L.T., and S. Lawrence, Grantmakers Describe the Impact of the Economic Crisis on Their Giving, New York: Foundation Center, 2009.

4. See also Lawrence, S., A First Look at the Foundation and Corporate Response to the Economic Crisis, New York: Foundation Center, 2009. 5. Ibid. 


\section{Mapping the Safety Net in Real Time}

The Foundation Center is constantly monitoring and collecting the most recent data on U.S. foundation and corporate support in response to the economic crisis. This information is easily accessed at foundationcenter.org on an interactive map displaying grants and program-related investments (PRIs), which is updated weekly and supplemented by a daily RSS grant feed. The map details more than $\$ 175$ million in support to date. To submit grants data for inclusion, please contact Matthew Ross, manager of special data projects, at mr@foundationcenter.org.

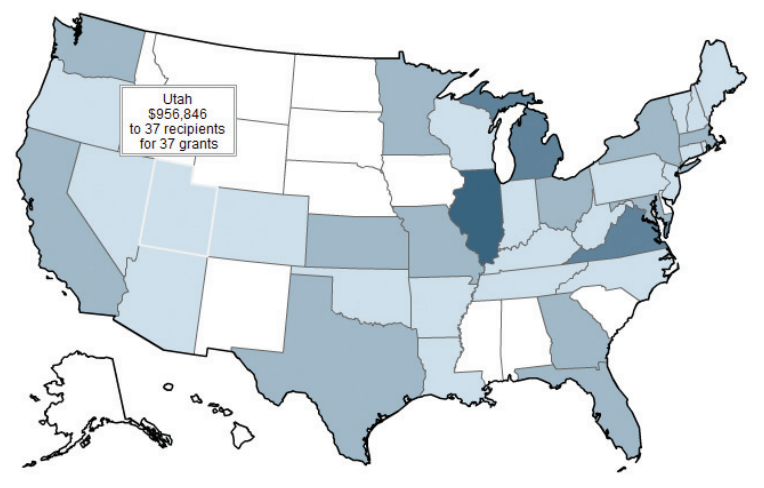

\section{About the Foundation Center}

Established in 1956, and today supported by close to 600 foundations, the Foundation Center is the nation's leading authority on organized philanthropy, connecting nonprofits and the grantmakers supporting them to tools they can use and information they can trust. The Center maintains the most comprehensive database on U.S. grantmakers and their grants and conducts research on trends in foundation growth, giving, and practice. It also operates education and outreach programs that help nonprofit organizations obtain the resources they need. Thousands of people visit the Center's web site each day and are served in its five regional learning centers and through its network of more than 400 funding information centers located in every U.S. state and beyond. For more information, visit foundationcenter.org or call (212) 620-4230.

\section{Source for all data:}

The Foundation Center

For more information about this advisory, contact communications@foundationcenter.org.

This study was made possible in part by support from The Wallace Foundation. Opinions represent those of the authors and not necessarily those of the Foundation.

The Foundation Center's Research Institute is funded in part by The Wallace Foundation, which seeks to support and share effective ideas and practices that expand learning and enrichment opportunities for all people. Its three current objectives are:

- Strengthen education leadership to improve student achievement

- Enhance out-of-school learning opportunities

- Build appreciation and demand for the arts

For more information on these and other related topics, please visit the Knowledge Center at wallacefoundation.org. 